
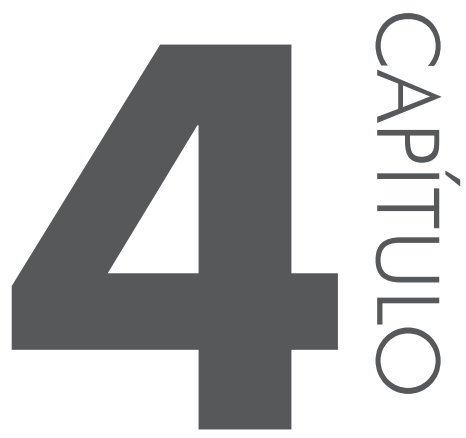

\title{
A selfie de Pero Vaz de Caminha: novos gêneros na aula de Literatura
}

Valéria Arauz ${ }^{1}$

Uma classe composta por adolescentes que recentemente iniciaram o estudo sistemático da literatura pode ser encarada como um grande desafio para qualquer professor. A maneira como o currículo ainda está organizado para o estudo das literaturas de língua portuguesa ${ }^{2}$ no Ensino Médio é em parte responsável por deixar muitos docentes apreensivos, pois prioriza o ensino da historiografia literária, ou seja, a classificação das obras em períodos e/ou escolas literárias, que

1 Doutora em Estudos Literários, atuou no Colégio de Aplicação da Universidade Federal do Maranhão (UFMA) de 2010 a 2014, ministrando a disciplina de Língua Portuguesa e Literatura nas três séries do Ensino Médio.

2 Literatura portuguesa, literatura brasileira e literaturas de países lusófonos africanos. 
precisam ser conhecidos, compreendidos, quando não memorizados seus autores e principais características.

Apesar do aconselhamento contrário das diretrizes curriculares nacionais (BRASIL, 1999; 2002; 2006), que orientam uma prática voltada para o estudo do texto e consideram o contexto como elemento extratextual necessário, mas não norteador do currículo, essa organização curricular e suas consequências metodológicas permanecem presentes em escolas e livros didáticos como possíveis meios para minimizar uma suposta lacuna existente entre o aluno, estereotipado como alguém que não tem a disciplina e o conhecimento prévio exigidos para a leitura literária, e a obra, que aparece de modo anacrônico na sala de aula. Seguem-se, então, os resumos copiados da internet, os esquemas de características dos estilos de época, biografias importadas das enciclopédias digitais e outras maneiras equivocadas de abordagem do texto literário. Como consequência, temos a cena descrita nas orientações curriculares do MEC:

Os professores, pressionados por programas panorâmicos, sentem-se obrigados a cobrir toda a linha do tempo (assim como se sentem pressionados a cobrir todos os pontos de gramática), fazendo uso da história da Literatura, ainda que isso não sirva para nada: aulas "chatas", alunos e professores desmotivados, aprendizagem que não corresponde ao que em princípio foi ensinado (BRASIL, 2006, p. 76).

Essa caracterização não é particular a algumas escolas, mas tem se tornado recorrente, mesmo entre as mais novas gerações de professores. Estes, ainda que tenham buscado a carreira das letras como entusiastas da leitura, não conseguem encontrar meios para se desgarrarem do modo como estudaram literatura na escola básica. É necessária, portanto, uma reflexão sobre como a escola pode proporcionar aos alunos a prática de uma leitura literária que os leve não apenas ao conhecimento de textos e autores, mas ao efetivo letramento literário (KLEIMAN, 1993; SOARES, 2003), quando podem apropriar-se da obra e seus múltiplos significados e atribuir-lhe o sentido único pertencente a cada leitor.

Os Parâmetros Curriculares Nacionais apresentam de modo mais geral, entre os objetivos para o ensino das linguagens, códigos e suas tecnologias, o estabelecimento de uma relação ampla e complexa entre o aluno, sujeito proficiente no uso da língua, e as mais diversas manifestações da linguagem. Esta relação prevê o diálogo entre o popular e o erudito, o atual e o canônico, o individual e o cultural.

Dentre os objetivos para a área de linguagens, este trabalho esteve relacionado diretamente com dois:

- analisar, interpretar e aplicar os recursos expressivos das linguagens, relacionando textos com seus contextos, mediante a natureza, função, organização e estrutura das manifestações, de acordo com as condições de produção e recepção; 


\section{$[\ldots]$}

- entender o impacto das tecnologias da comunicação e da informação na sua vida, nos processos de produção, no desenvolvimento do conhecimento e na vida social (BRASIL, 2002, p. 95).

Diante da impossibilidade de alterações no currículo, já que estas não estavam previstas no projeto pedagógico da escola e interfeririam no planejamento de um grupo maior de professores, procuramos adequar as nossas atividades à sequência preestabelecida de conteúdos, e ainda oferecer aos alunos um modo diferente de abordagem do texto e dos conhecimentos contextuais relacionados ao trabalho com a obra literária.

O texto da Carta de Pero Vaz de Caminha está contemplado pelo currículo no $1^{\circ}$ ano do Ensino Médio, e é estudado como parte do Quinhentismo ${ }^{3}$. Neste momento, é apresentada para o aluno uma estética de transição, não apenas na forma do texto literário, mas, como parte da abordagem da historiografia literária, pois, pela primeira vez o Brasil entra em foco, mesmo que ainda seja como matéria temática para a produção literária de Portugal. Para além disso, é notória a importância desse texto para o estudante brasileiro, mesmo que inicialmente não sendo tomado como uma obra literária, por não se tratar de um texto ficcional.

Bakhtin (1997), ao trabalhar a relação entre o autor e o contexto literário, nota como a relação entre a palavra e o mundo permite o diálogo entre o artista, que tem uma relação imediata com o objeto descrito/narrado, e o mundo construído ficcionalmente. Segundo ele,

o contexto real de valores que dá sentido à obra do autor nunca coincide com o contexto estritamente literário, e menos ainda se este é entendido de um modo real-materialista; este contexto, claro, insere-se com seus valores no primeiro, onde entretanto figura na qualidade de determinado e não na de determinante (BAKHTIN, 1997, p. 209).

Assim, é possível pensarmos na Carta como uma composição literária sobre a terra recém-descoberta, mesmo que esta não fosse a primeira intenção de Caminha. A mediação verbal realizada pelo escrivão da esquadra Cabrália associa os elementos "fônicos, emocionais e pitorescos" (BAKHTIN, 1997, p. 209), próprios de uma produção artística, e permite que tratemos esse documento histórico como um gênero singular, em que, mesmo se pretendendo realista (factu-

3 Período literário que se estende ao longo do século XVI e marca o início da literatura produzida em terras brasileiras, em seu período colonial. Na classificação historiográfica, compreende uma literatura informativa, dos viajantes e cronistas, e uma literatura formativa, praticada pelos jesuítas. 
al), o autor conta em sua escrita com o verossímil próprio da escrita ficcional ao descrever os primeiros dias dos portugueses na costa brasileira.

Alfredo Bosi, ao apresentar A Carta em sua História concisa da literatura brasileira, faz referência a esse fato e assim o explora:

a pré-história das nossas letras interessa como reflexo da visão do mundo e da linguagem que nos legaram os primeiros observadores do país. Graças a essas tomadas diretas da paisagem, do índio e dos grupos sociais nascentes, que captamos as condições primitivas de uma cultura que só mais tarde poderia contar com o fenômeno da palavra-arte (BOSI, 1994, p. 13).

Essa discussão aparece nos livros didáticos e precisa ser apresentada aos alunos, pois, mesmo sendo um documento escrito por um português para o rei de Portugal, assim como ocorre em todas as crônicas da chamada literatura de viajantes, A Carta foi matéria de referência para diversos escritores da nascente literatura brasileira, tanto no século XIX - José de Alencar e Gonçalves Dias - como na consolidação de nossa poética por Mário de Andrade e Oswald de Andrade. Este último já aparece nos livros didáticos por meio do seu poema Pero Vaz Caminha, como uma tentativa bastante atual de quebrar a linearidade de um discurso historiográfico da literatura, em que os textos são expostos de maneira estanque, sem fazer referência às diversas intertextualidades e aos movimentos de retomada - parafrásica ou paródica - dos textos que primeiro retrataram uma realidade brasileira.

Não deveria ser necessário, por exemplo, o aluno chegar ao último ano do Ensino Médio para se problematizar o que é, de fato, uma literatura brasileira. A leitura da Carta pode, em um movimento de antecipação, sinalizar a evolução do pensamento de criação de uma cultura nacional, desde uma visão idílica da pátria, como em Caramuru, Iracema, na Canção do Exílio, até o humor ácido presente no Macunaíma ou nos poemas de Pau Brasil ${ }^{4}$, ou ainda na visão de uma brasilidade presente em Drummond ou Guimarães Rosa.

No início do ensino sistemático de literatura, neste mesmo ano escolar, os alunos são apresentados às características e funções da linguagem literária. A compreensão sobre como se forma o conjunto de obras que caracterizam a literatura brasileira, sua função social, e como essas obras foram determinantes para a construção de uma

4 O poema épico Caramuru, do Frei José de Santa Rita Durão, ainda será estudado sistematicamente no $1^{\circ}$ ano do Ensino Médio; já Iracema, de José de Alencar e a poesia de Gonçalves Dias deverão ser conhecidos pelos alunos apenas no ano seguinte; Mário de Andrade, autor de Macunaíma e Oswald de Andrade, de Pau Brasil, serão estudados somente no último ano, com o estudo do primeiro modernismo e dos autores mais recentes como Carlos Drummond de Andrade e João Guimarães Rosa. 
língua brasileira e de todo um conjunto cultural, ao longo de cinco séculos, é imperioso para a formação de um sujeito crítico e atento às nuances históricas e culturais de seu país.

Antônio Cândido (1993, p. 29), por outro lado, endossa a manutenção de um caráter historiográfico dos estudos literários, pois, para ele, "o desejo de compreender todos os produtos do espírito, em todos os tempos e lugares, leva, fatalmente a considerar o papel da obra no contexto histórico, utilizando este conhecimento como elemento de interpretação e, em certos casos, avaliação". O desafio para o professor de língua é conseguir harmonizar essa relação entre o estudo da obra em sua textualidade e o papel que esta desempenhou em determinada cultura e período histórico, inclusive como lente leitora dessa época, sem deixar-se levar por um estudo de datas, nomes e clichês literários transmitidos mecanicamente no decorrer de anos.

Estudar, portanto, A Carta, seu contexto de produção e seus desdobramentos literários era um desafio que valia a pena ser aceito e precisava ser levado aos alunos de uma forma motivadora.

A busca por pontos de convergência entre o texto estudado e os leitores adolescentes levou-nos à seguinte reflexão: Caminha precisou usar o único recurso de que dispunha para revelar ao rei $\mathrm{D}$. Manuel I as informações sobre as novas terras que a esquadra Cabrália havia aportado. Como esses meninos e meninas, que vivem em um contexto urbano no qual o gênero carta está quase extinto, fariam para reportar as imagens de uma viagem completamente nova a seus parentes, amigos ou mesmo em um relatório? Pensamos, então, no gênero selfie, tão atual quanto difundido entre os adolescentes. Se Caminha tivesse um celular, portanto, ele teria feito selfies no Brasil, foi a conclusão a que chegamos.

O gênero selfie pareceu adequar-se perfeitamente ao propósito do escrivão português para A Carta, pois ele, enquanto mostrasse ao rei as riquezas do Brasil, mostrar-se-ia também como sujeito perplexo misturado à nova paisagem que se desenhava diante de si, sujeito imbuído de uma ideologia mercantilista e catequista.

Assim, empreendemos a sequência didática que tomou quatro aulas de $50 \mathrm{mi}-$ nutos mais uma atividade extraclasse com as fotografias - produção das selfies. A proposta foi denominada A selfie: Caminha não teria escrito A Carta se tivesse um celular, e será narrada a seguir:

Os alunos haviam estudado anteriormente Os lusíadas e as diversas implicações que o período das Grandes Navegações trouxera para o povo português. Fizemos, então, uma breve contextualização histórica da descoberta do Brasil. Nesse momento, foi trazida para a sala de aula a canção Pindorama (PERES; TATIT, 2004), do grupo Palavra Cantada, da qual seguem alguns trechos: 


$\begin{array}{ll}\begin{array}{l}\text { Pindorama } \\ \text { (Terra à vista!) }\end{array} & \begin{array}{l}\text { Só depois, vêm vocês } \\ \text { Que falavam tupi-português } \\ \text { Só depois com vocês } \\ \text { Nossa vida mudou de uma vez }\end{array} \\ \begin{array}{l}\text { Pindorama, Pindorama } \\ \text { É o Brasil antes de Cabral } \\ \text { Pindorama, Pindorama } \\ \text { É tão longe de Portugal }\end{array} & {[\ldots]} \\ \text { Fica além, muito além } & \text { Pero Vaz, Pero Vaz } \\ \text { Do encontro do mar com o céu } & \text { Disse em uma carta ao rei } \\ \text { Fica além, muito além } & \text { Que num altar, sob a cruz } \\ \text { Dos domínios de D. Manuel } & \text { Rezou missa o nosso frei } \\ & \text { Mas depois seu Cabral } \\ \text { [...] } & \text { Foi saindo devagar } \\ \text { Pindorama, Pindorama } & \text { Do país tropical } \\ \text { Mas os índios já estavam aqui } & \text { Para as Índias encontrar } \\ \text { Pindorama, Pindorama } & {[\ldots . .]} \\ \text { Já falavam tudo em tupi } & \end{array}$

Pindorama, nome atribuído à terra pelos indígenas, logo seria transformada em Ilha de Vera Cruz, Terra de Santa Cruz e, finalmente, Brasil. Discutimos sobre esta mudança de nomes e de visões sobre a terra, a partir da letra da canção. Além disso, os alunos também foram questionados sobre como eles imaginavam as primeiras impressões causadas tanto pelos índios aos portugueses, como o contrário. O estranhamento entre culturas e sujeitos foi debatido também com auxílio do poema Erro de português, de Oswald de Andrade (2003):

\author{
Erro de português \\ Quando o português chegou \\ Debaixo de uma bruta chuva \\ Vestiu o índio \\ Que pena! \\ Fosse uma manhã de sol \\ O índio tinha despido \\ O português.
}

Depois apresentamos aos alunos diversas influências que o primeiro documento sobre o Brasil trouxe para a nossa cultura. Pinturas de Pedro Américo, poemas dos modernistas, e mesmo a história do descobrimento ilustrada pelo cartunista Maurício de Sousa vieram para esta aula.

Como escolha metodológica, optamos, sempre que possível, pela leitura na íntegra das obras estudadas. No caso do texto da Carta, o acesso ao texto integral enriqueceu bastante a experiência de leitura dos alunos.

Ao fim da aula introdutória, os alunos tiveram acesso a uma versão fotocopiada do texto original. Essa primeira leitura deveria ser feita em casa ou no ambien- 
te que melhor lhes conviesse. O contato com A Carta, no entanto, ocorreu conforme a expectativa de uma resistência inicial, ou seja, dos 38 alunos que levaram o texto para casa, nenhum deles referiu tê-lo lido na íntegra. Essa dificuldade era esperada, pois o texto sugerido não corresponde ao repertório desses leitores em formação, por causa do seu alto teor descritivo e do uso, bem distinto do cotidiano dos adolescentes, de uma linguagem rebuscada e formal.

Mesmo alguns professores, muitas vezes, não leem a obra estudada e se detêm ao acesso de material sobre o texto. Desse modo, repetem as informações fornecidas pelo livro didático: contextualização; biografia sucinta do autor; amostras de excertos significativos do texto, como, no caso da Carta, os fragmentos que relatam a nudez das índias e o contato dos nativos com animais vindos de Portugal; e curiosidades sobre o momento histórico relatado no texto.

Neste caso, diante das queixas trazidas pelos alunos, procedemos, então, uma leitura coletiva do material. Na classe, dois horários foram requeridos para que, em voz alta, fosse lida A Carta, parágrafo por parágrafo, com a participação de todos os estudantes. Intervenções pontuais eram feitas, ora para retomarmos por paráfrase o texto lido até então, com o intuito de construir coletivamente a imagem descrita por Caminha, ora para elucidarmos o significado de alguma palavra ou expressão arcaica ou de significado desconhecido. ${ }^{5}$ Aos poucos a realidade elaborada pelo escrivão português foi ganhando vida na sala de aula. Os alunos puderam vislumbrar as naus portuguesas adentrando a primeira baía avistada em terras brasileiras. Com a ajuda de um mapa grosseiramente desenhado na lousa, ganharam dimensões e proporções as naus e os batéis dos navegantes; os índios que dia a dia acresciam-se no contato com os visitantes - no início três ou quatro, até chegarem às centenas; a lista de tentativas de contato estabelecidas entre o capitão português e os nativos e as ofertas que serviam para amansá-los; e a exposição (e imposição) da religiosidade portuguesa àqueles que aparentemente não professavam fé alguma, segundo o relato do escrivão.

Além do recurso da explicação concomitante à leitura, alguns alunos também faziam observações ao que estava sendo lido, e as trocas em sala de aula foram imprescindíveis para a construção de uma referenciação ao texto lido, favorecendo o processo de leitura plena do texto, com vistas à fruição primeira da obra. Cada palavra, outrora desconhecida, ao ser repetida ao longo da narração, logo passava a soar como familiar e somava-se às demais para formar a cena da enunciação do texto de Pero Vaz de Caminha.

5 Na preparação da aula, já havíamos buscado em dicionários e enciclopédias o significado de palavras como botelho, batel, esquife, aljaveira, amainar, arribar, almadia, solapa, toutiço, entre outras. Estas pertencem ao campo semântico de palavras da navegação ou eram próprias do vocabulário da época. 
O papel do professor se ressalta em um caso como este. Ele precisa ser responsável não apenas por apresentar o texto ao aluno, mas também, muitas vezes, toma o lugar de guia, apontando caminhos de leitura e os índices para que chegue ao final do texto com a significação ampla sobre aquilo que leu e possa fazer suas próprias interpretações e apropriação dos sentidos resultados dessa leitura.

O segundo passo, depois de realizada essa leitura de reconbecimento do texto de Caminha, foi a contextualização da obra, com vistas a uma leitura crítica do relato quinhentista de Caminha.

No livro didático adotado pela escola ${ }^{6}$ (RAMOS, 2012), há um capítulo sobre as "origens da literatura brasileira", no qual são destinadas uma seção e mais uma página de exercícios para A Carta. Essa explanação foi útil para auxiliar na exposição dos diversos gêneros - roteiros náuticos, relatos de naufrágios, diários de bordo - que circulavam no início do século XVI, dos quais A Carta concentra diversas características em um formato epistolar. Além dessa informação, o manual do aluno apresenta apenas um fragmento emblemático de cinco linhas que descreve a nudez das índias e finaliza a discussão com a ressalva de que "a Carta de Caminha revela características de uma significativa variedade de gêneros textuais e grande habilidade narrativa" (RAMOS, 2012, p. 120).

Umberto Eco (1986), no seu Lector in fabula, afirma que o leitor percorre um caminho desde a primeira leitura de um texto até tornar-se capaz de levantar elementos críticos da obra explorada. Seguindo esta proposição, a leitura do texto de Caminha motivou uma busca por diversos elementos que não apenas mostravam a postura do descobridor diante das novas terras, mas também as limitações da linguagem de que Caminha dispunha para descrever algo completamente novo ao rei D. Manuel.

Uma dessas dificuldades percebidas pelos alunos foi em relação à adjetivação. O primeiro contato com elementos desconhecidos foi um grande desafio linguístico para o escrivão. Ao descrever, por exemplo, a aparência dos índios, ele não tinha uma palavra para o cocar:

um deles trazia por baixo da solapa, de fonte a fonte para detrás, uma espécie de cabeleira de penas de ave amarelas, que seria do comprimento de um coto, mui basta e mui cerrada, que lhe cobria o toutiço e as orelhas. E andava pegada aos cabelos, pena e pena,

6 Esta atividade foi desenvolvida no colégio de aplicação da Universidade Federal do Maranhão Colégio Universitário (COLUN). Como escola pública, o Colégio Universitário tem acesso ao PNLEM (Programa Nacional do Livro do Ensino Médio) e escolhe livros pedagogicamente avaliados pelo MEC. O livro utilizado no ano de 2014 foi considerado pelos professores a melhor escolha dentre aqueles apresentados, por conter a maior representatividade de textos e excertos de obras, em detrimento da mera apresentação de biografias e contextualização de estilos literários. 
com uma confeição branda como cera (mas não o era), de maneira que a cabeleira ficava mui redonda e mui basta, e mui igual, e não fazia míngua mais lavagem para a levantar (CAMINHA, 2015, p. 3).

Os adolescentes perceberam essa falta de vocabulário para tudo o que envolvia a cultura indígena, e puderam evidenciar a capacidade descritiva de Caminha, ao reportar ao rei D. Manuel as imagens da flora e fauna brasileiras, plantas e animais nunca antes vistos pelo regente português.

Além disso, também pareciam-lhes novas as notações matemáticas para relacionar as medidas e quantidades. Por exemplo, "[e]ntraram todas as naus dentro; e ancoraram em cinco ou seis braças - ancoragem dentro tão grande, tão formosa e tão segura, que podem abrigar-se nela mais de duzentos navios e naus" (CAMINHA, 2015, p. 4, grifo nosso). A imprecisão de algumas medidas, como "dois tiros de besta" (CAMINHA, 2015, p. 13), chamou a atenção da turma. Eles conheciam a besta, por causa dos jogos de videogame com temática medieval, e puseram-se a tentar precisar a distância que os índios tomavam para acompanhar o avanço dos portugueses. Vale ressaltar, porém, que essa fosse talvez a maneira disponível à época para referenciar os padrões de pesos e medidas, mesmo que hoje nos pareça rudimentar, e isso também foi discutido na sala, suscitando o interesse para que posteriormente procurássemos o professor de matemática para um estudo interdisciplinar.

Também ficou evidente durante a aula o caráter catequizador da postura dos portugueses diante dos índios, conforme observou Alfredo Bosi:

Espírito observador, ingenuidade (no sentido de um realismo sem pregas) e uma transparente ideologia mercantilista batizada pelo zelo missionário de uma cristandade ainda medieval: eis os caracteres que saltam à primeira leitura da Carta e dão sua medida como documento histórico (BOSI, 1994, p. 14).

Este talvez tenha sido o traço mais marcante da Carta. Os alunos se posicionaram de modo contrário à ideia de Caminha de que aqueles homens não professavam fé alguma: "por onde nos pareceu a todos que nenhuma idolatria, nem adoração têm" (CAMINHA, 2015, p. 13-14). Fizeram referência ao fato de que as religiões ancestrais indígenas eram fortemente marcadas em sua cultura e o olhar ideologicamente determinado de Caminha teria sido fundamental para que não percebesse esse traço cultural dos indígenas.

Chamou-lhes atenção também a ingenuidade dos índios em relação aos presentes oferecidos e às investidas dos portugueses. As cenas das missas e o olhar de Caminha para os índios como futuras ovelhas de um rebanho cristão e súditos de D. Manuel também foram impactantes, e o fragmento a seguir foi bastante debatido por causa da aparente facilidade com que os indígenas se submetiam ao seu colonizador: 
Acabada a missa, tirou o padre a vestimenta de cima e ficou em alva; e assim se subiu junto com altar, em uma cadeira. [...] Esses, que à pregação sempre estiveram, quedaram-se como nós olhando para ele. E aquele, que digo, chamava alguns que viessem para ali. Alguns vinham e outros iam-se. E, acabada a pregação, como Nicolau Coelho trouxesse muitas cruzes de estanho com crucifixos, que lhe ficaram ainda da outra vinda, houveram por bem que se lançasse a cada um a sua ao pescoço. Pelo que o padre frei Henrique se assentou ao pé da Cruz e ali, a um por um, lançava a sua atada em um fio ao pescoço, fazendo-lha primeiro beijar e alevantar as mãos. Vinham a isso muitos; e lançaram-nas todas, que seriam obra de quarenta ou cinquenta (CAMINHA, 2015, p. 5-13, grifo nosso).

Finalmente, procedeu-se à leitura do poema Pero Vaz Caminha, do livro Pau Brasil, de Oswald de Andrade (2003):

\section{Pero Vaz Caminha}

\section{A descoberta}

Seguimos nosso caminho por este mar de longo

Até a oitava da Páscoa

Topamos aves

E houvemos vista de terra

Os selvagens

Mostraram-lhes uma galinha

Quase haviam medo dela

E não queriam por a mão

E depois a tomaram como espantados

Primeiro chá

Depois de dançarem

Diogo Dias

Fez o salto real

\section{As meninas da gare}

Eram três ou quatro moças bem moças e bem gentis

Com cabelos mui pretos pelas espáduas

E suas vergonhas tão altas e tão saradinhas

Que de nós as muito bem olharmos

Não tínhamos nenhuma vergonha

A transcrição de fragmentos da carta de Caminha foi enfatizada em relação ao tom paródico que a escolha e disposição desses elementos impõem ao texto original. Desde a supressão da preposição de, que transforma o nome do escrivão português em verbo, os alunos perceberam que os trechos selecionados do documento original denunciam a visão do português sobre a terra recém-descoberta, e quantos desses elementos e estereótipos se cristalizaram na cultura brasileira ao 
longo dos séculos. O poema, de 1925, redimensiona os sentidos do texto de 1500 e revela os problemas de uma visão ainda eurocêntrica da cultura brasileira.

A última etapa do trabalho com o texto foi a proposição da atividade com as selfies. Segundo o Oxford Dictionary (2015), a selfie é "um autorretrato feito por meio de um celular ou de uma webcam e imediatamente compartilhado nas redes sociais". 7 Eleito a palavra do ano em 2013, o termo selfie não se popularizou apenas como um vocábulo, mas como um novo modo de apresentar-se diante das redes sociais. A concepção do gênero, como também sua execução, características e função social são bastante familiares aos adolescentes e a reação da turma de $1^{\circ}$ ano foi de extrema empolgação.

Eles agora estariam no lugar de Caminha, não mais com a pena e habilidades linguísticas, mas com as câmeras de seus aparelhos celulares. Seriam responsáveis pela composição das fotografias, que deveriam fazer referência explícita ao texto da Carta, ressaltando os fragmentos que mais lhes haviam chamado a atenção. Foi-lhes solicitado imaginar como Pero Vaz de Caminha teria divulgado a descoberta portuguesa nas redes sociais.

O resultado foi bastante satisfatório. ${ }^{8}$ Alguns grupos buscaram cenários aproximados àqueles do descobrimento do Brasil (Figura 4.1 e Figura 4.2) e, mesmo tendo sido prevenidos sobre os cuidados com a exibição de seus corpos, fizeram questão de retratar a beleza das índias (Figura 4.1, Figura 4.2 e Figura 4.3).

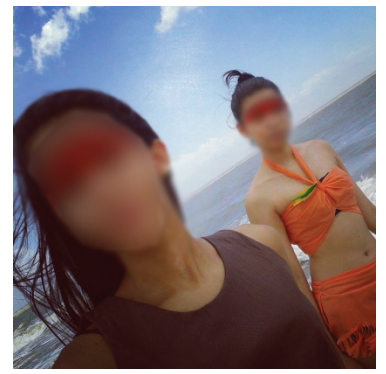

Figura 4.1 - Tentativa de reprodução das pinturas indígenas, conforme descrito por Caminha.

7 Tradução nossa. Texto original: "A photograph that one has taken of oneself, typically one taken with a smartphone or webcam and shared via social media”.

8 Esta é uma amostra das fotos encaminhadas como resultado do trabalho. O uso das imagens dos alunos foi autorizado por seus responsáveis legais, por meio de assinatura de um termo de consentimento de uso e cessão dos direitos de imagens. 


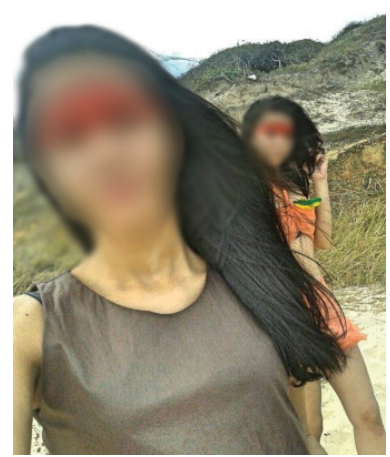

Figura 4.2 - Autorretrato da índia. As praias onde aportaram os portugueses.

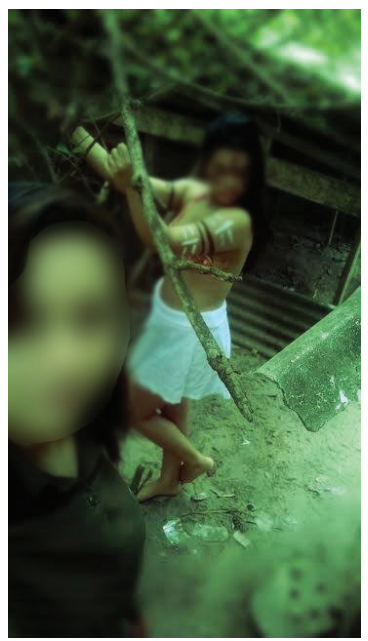

Figura 4.3 - Portuguesa mostra a beleza da índia. Note-se a preocupação em remover, por meio de edição, os elementos contemporâneos da foto.

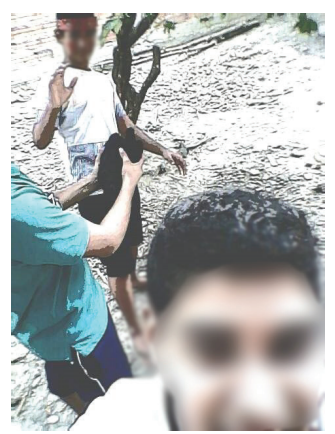

Figura 4.4 - Português registra o momento em que o índio se assusta ao ver, pela primeira vez, uma galinha. 


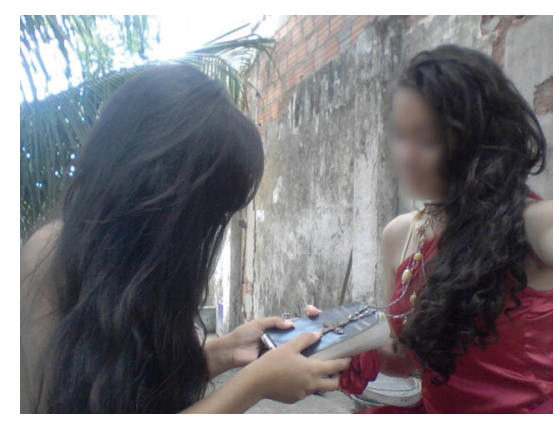

Figura 4.5 - Portuguesa registra o primeiro contato da índia com a Bíblia e com a cruz.

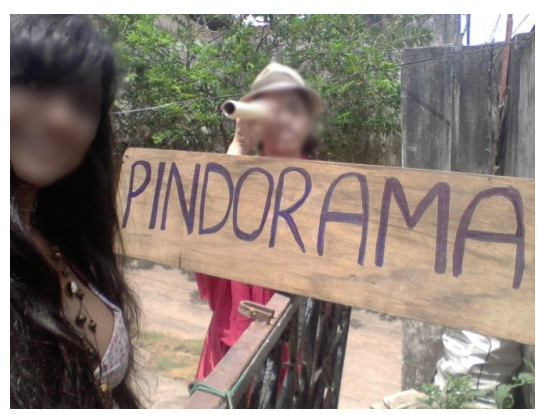

Figura 4.6 - Índia apresenta o nome original da terra avistada pelos portugueses.

A maioria dos grupos foi fiel às características do gênero selfie, e em todos os exemplos apresentados (Figuras 4.1 a 4.6) nota-se a imagem do fotógrafo destacada em primeiro plano, ou a exibição do braço que segura a câmera, incluindo objeto e fotógrafo em uma mesma cena. Os temas de Caminha se preservaram nas imagens e mostraram o quanto as impressões do escrivão português ficaram incutidas na mente de cada estudante. As fotos teriam legendas sugeridas pelos próprios alunos para serem publicadas em rede social e permitiram identificar a que fragmento da Carta correspondem, denotando uma preocupação em uma tradução semiótica entre os gêneros carta e selfie, com a preservação dos elementos originais.

Ao produzir suas selfies, cada grupo pôde experimentar a focalização narrativa do próprio Pero Vaz de Caminha. Não se contentando em descrever objetivamente a paisagem e os nativos que observara, o narrador construído por Caminha se insere na cena, pelo seu olhar e pela adjetivação que demonstra sua perplexidade diante do insólito. Essa é a visão cultural sobre o objeto, que também se reproduz na selfie: não basta ao sujeito mostrar um elemento, mas a sua participação na composição da cena vai além da narração objetiva e apresenta o sujeito como parte dessa composição fotográfica. 
Note-se, ainda, que nas selfies dos alunos não apenas os portugueses são sujeitos, mas também os índios se retratam, mostrando-se e apresentando o nome indígena de sua terra na placa Pindorama.

A última etapa do trabalho foi a publicação das fotos na rede social Facebook, com a legenda A selfie de Pero Vaz de Caminha - Caminha escreveu carta porque não tinha celular... Trabalho dos Alunos do $1^{\circ}$ Ano $D$. As fotos receberam mais de 60 notificações positivas e 11 comentários, mesmo tendo sido compartilhadas em um modo restrito. Os alunos demonstraram empenho na realização da atividade e tiraram proveito da leitura, que ultrapassou os objetivos da aula de Literatura e se mostrou um exercício de interpretação e transcodificação entre os gêneros trabalhados: epistolar, poema e selfie.

A avaliação da atividade foi positiva e, mesmo após quase um ano de sua realização, tempo em que foi escrito este relato, os alunos ainda mencionam o trabalho com as selfies e o texto de Caminha como algo que os marcou em sua formação de leitores. Esse conhecimento ficou consolidado e certamente será retomado sempre que algum outro texto fizer referência à Carta, quer no estudo da Literatura Brasileira, ou mesmo nas aulas de Artes, História ou Sociologia.

A literatura atua, assim, como formadora de um escopo cultural bastante significativo para os adolescentes, que, dotados das ferramentas adequadas para manejarem o texto, conseguem apropriar-se de seus múltiplos sentidos, transportando a experiência para novas leituras e por toda a vida, como parte de si.

\section{Referências}

ANDRADE, O. de. Pau-Brasil. In: SCHWARTZ, J. (Org.). Caixa modernista. São Paulo: EDUSP: Imprensa Oficial; Belo Horizonte: UFMG, 2003. Edição fac-similar.

BAKHTIN, M. Estética da criação verbal. Tradução de Maria Ermantina Galvão G. Pereira. São Paulo: Martins Fontes, 1997.

BOSI, A. A condição colonial. In: . História concisa da literatura brasileira. 34. ed. São Paulo: Cultrix, 1994.

BRASIL. Ministério da Educação. Parâmetros Curriculares Nacionais - Ensino Médio. Área de linguagens, códigos e suas tecnologias. Brasília: Secretaria de Educação Média e Tecnológica/MEC, 1999.

. Ministério da Educação. Secretaria de Educação Básica. PCN+. Linguagens, códigos e suas tecnologias. Brasília: MEC/SEB, 2002. 244p. (Orientações Educacionais Complementares aos Parâmetros Curriculares Nacionais). Disponível em: <http://portal. mec.gov.br/seb/arquivos/pdf/linguagens02.pdf>. Acesso em: 5 maio 2015.

- Ministério da Educação. Secretaria de Educação Básica. Linguagens, códigos e suas tecnologias. Brasília: MEC/SEB, 2006. 239p. (Orientações curriculares para o Ensino Médio, 1). 
CAMINHA, P. V. de. A carta. Disponível em: <http://objdigital.bn.br/Acervo_Digi tal/livros_eletronicos/carta.pdf>. Acesso em: 12 maio 2015.

CÂNDIDO, A. Formação da literatura brasileira. 7. ed. Rio de Janeiro: Itatiaia, 1993. v. 1. ECO, U. Lector in fabula: a cooperação interpretativa nos textos narrativos. São Paulo: Perspectiva, 1986.

KLEIMAN, A. Oficina de leitura: teoria e prática. Campinas: Unicamp, 1993.

OXFORD DICTIONARY. Selfie. Disponível em: <http://www.oxforddictionaries.com/ pt/definição/inglês-americano/selfie>. Acesso em: 12 maio 2015.

PERES, S.; TATIT, P. Pindorama. In: . Palavra Cantada 10 anos. São Paulo: MCD, 2004. 1 CD. Faixa 2.

RAMOS, R. de A. (Org.). Coleção ser protagonista: Língua Portuguesa, $1^{\circ}$ ano: Ensino Médio. São Paulo: SM, 2012.

SOARES, M. Alfabetização e letramento. 5. ed. São Paulo: Contexto, 2003 
